\title{
Framework for Detecting Dyslexia
}

\section{Suyash Thonte ${ }^{1}$, Risha Saxena ${ }^{2}$, Shubham Swami ${ }^{3}$, Onkar Kamthe ${ }^{4}$, Prof. Pallavi Shimpi ${ }^{5}$}

${ }_{1,2,3,4}$ Student, Department of Computer Engineering, Dr. D. Y. Patil School of Engineering, Lohegoan Savitribai Phule Pune University, Pune, Maharashtra, India

${ }^{5}$ Professor, Department of Computer Engineering, Dr. D. Y. Patil School of Engineering, Lohegoan Savitribai Phule Pune University, Pune, Maharashtra, India

\begin{abstract}
In this paper we present a Big data-based multimedia System, which uses text, audio, video, Pattern Recognition and Facial Recognition along with Eye-Tracking to detect a set of symptoms of having dyslexia among children. Several test modules have been developed, which gives indications of dyslexia diagnosis. Also Eye Tracking and Facial Recognition gives a furthermore Precise results. The multimedia framework is envisioned to accelerate and ease the process of detecting dyslexia at the global level, and to predict the presence of disease in the individual and also determine the intensity of the disease.
\end{abstract}

Keywords : Test Modules, EyeTracking Algorithm, FacialRecognition, BigData, Pattern Recognition.

\section{INTRODUCTION}

Dyslexia is Learning disorder that involves difficulty reading due to problems identifying speech sounds and learning how they relate to letters and words (decoding). Also called reading disability, dyslexia affect areas of the brain that process language.

Although children with dyslexia tend to show gifted intelligence, the learning disability poses a great challenge to adapt to the normal learning styles in the school. Although various test mechanisms have been proposed in the past in diagnosing the presence of dyslexia among children in preschool and junior schools, most of them cannot be applied to a mass level or supports on single modality. Thanks to the recent advancements in multimedia technologies and Machine Learning, high speed Internet communication, even at rural areas, big data analytics, a new dimension of diagnosis of Dyslexia is now possible. In this system, a framework has been used where different Testing Modules and Eye Tracking have been proposed. The test can be administered by a school on a national level, where each individual test is graded by a licensed dyslexia therapist.

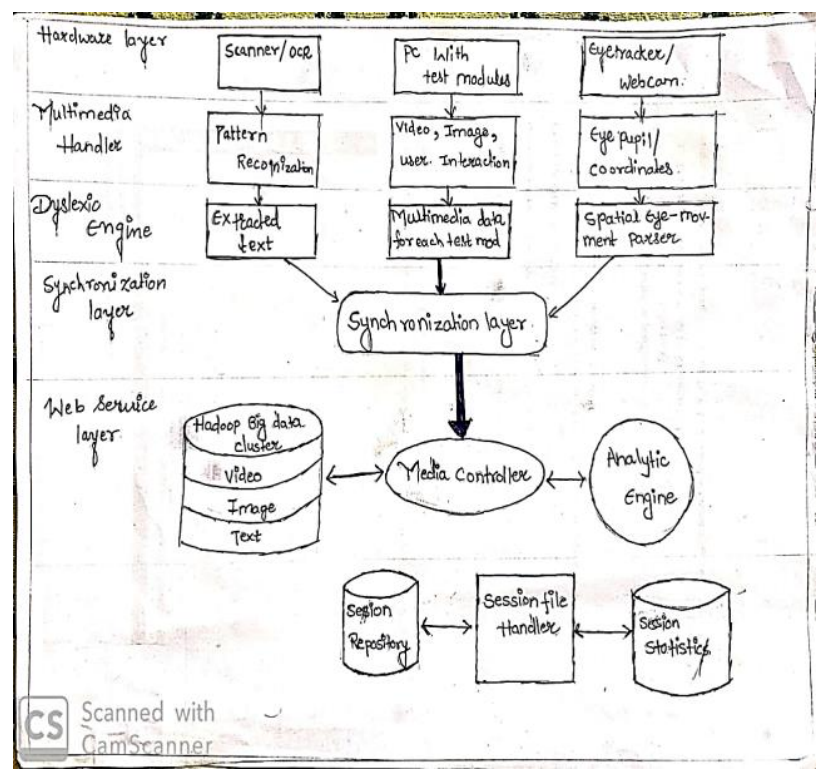

Figure 1 : Proposed System Architecture 
Each user interactions with the test modules are stored as a video along with the Gaze or Pupil movement. At the end of a test session, the tablet PC communicates with the cloud based big data environment where the multimedia data consisting of user typed text, user interaction with different test modules captured as a video and screen images are uploaded for a set of algorithms to detect Dyslexia phenomena.

The Algorithms try to automatically detect dyslexia from the available multimedia files and share the results with a Dyslexia therapist for further analysis.

The main goal of this project is to Develop a framework at a global level for detecting Dyslexia and to help the children to be cured at early stage.

\section{LITERATURE SURVEY}

In 2015, Dr. Luz Rello of Carnegie Mellon University used a machine learning model to automatically predict if readers were at a risk for dyslexia. Her model was based on a Support Vector Machine (SVM) binary classifier that trained on a dataset consisting of 1,135 videos (recorded using an eye tracker) of people with and without dyslexia reading. And while this was the first time that a combination of eye tracking and machine learning techniques had been used to identify a risk for dyslexia in practice, the model was relatively inaccurate, with a maximum $80.18 \%$ accuracy. It was also not scalable, as it required hefty eye tracking equipment that is only available in scientific laboratories. This makes it inaccessible to a majority of the population across the world.

Many groups have used machine learning to detect dyslexia using students' test scores as well as demographic or survey data as features (Kohli \& Prasad, 2010). Loizou and Laouris used the results of four tests for dyslexia as features in several machine learning techniques to diagnose students, amounting to 226 total features (2011). Costa et al. used a totalof144 features, including somehand-collected from interviews with families and students (asking about discipline, likingschool, having friends, etc.), to assess learning disabilities (2013). Others have successfully diagnosed dyslexia from computational classification of brain electrical activity (Duffy et al., 1980; Lehongre et al., 2013) or by tracking eye movements (De Luca et al., 2002). Very recent work by Rezvani et al. used machine learning to automate EEG (brainwave)and brain image analysis to potentially decrease the cost of brain screening tests (2019). Other work even combines EEG tests and genetic tests to diagnose dyslexia (Wilckeetal.,2015).

The overall finding of the above discussion is given below as Table-1

Table 1

\begin{tabular}{|l|l|l|l|}
\hline $\begin{array}{l}\text { Sr. } \\
\text { No. }\end{array}$ & Paper Name & Method Proposed & Limitations \\
\hline 1. & $\begin{array}{l}\text { ML to detect dyslexia } \\
\text {-Kohli and Prasad }\end{array}$ & $\begin{array}{l}\text { ML to detect dyslexia using students } \\
\text { test scores as well as demographic or } \\
\text { survey data as features }\end{array}$ & $\begin{array}{l}\text { Didn't have the Eye Tracking } \\
\text { Algorithm to accurately predict } \\
\text { Dyslexia }\end{array}$ \\
\hline 2. & $\begin{array}{l}\text { Risk of development } \\
\text { dyslexia } \\
\text { - Costa et al .(2013) }\end{array}$ & $\begin{array}{l}\text { Costa et al. used a totalof 144 features, } \\
\text { including some hand-collected from } \\
\text { interviews with families and students } \\
\text { (asking about discipline, liking school, } \\
\text { having friends, etc.), to assess learning } \\
\text { disabilities }\end{array}$ & $\begin{array}{l}\text { Limited to a few number of } \\
\text { students, Couldn't deploy on large } \\
\text { Scale and also Time Consuming }\end{array}$ \\
\hline
\end{tabular}




\begin{tabular}{|l|l|l|ll|}
\hline 3. & $\begin{array}{l}\text { Dyslexia tests } \\
\text { - Loizou \& Laouris }\end{array}$ & $\begin{array}{l}\text { Used results of } 4 \text { tests as features in } \\
\text { several ML techniques to diagnose } \\
\text { students, amounting to 226 features }\end{array}$ & $\begin{array}{l}\text { Eye-Tracking and Pattern } \\
\text { Recognition absent. }\end{array}$ \\
\hline 4. & $\begin{array}{l}\text { Dyslexia using EEG } \\
- \text { Wilckeetal }\end{array}$ & $\begin{array}{l}\text { Combine EEG tests and genetic tests } \\
\text { to diagnose dyslexia }\end{array}$ & $\begin{array}{l}\text { Not Cost Efficient and not } \\
\text { implemented at Global Level }\end{array}$ \\
\hline
\end{tabular}

\section{TAXONOMY CHART}

\begin{tabular}{|c|c|c|c|c|c|c|}
\hline $\begin{array}{l}\text { Paper } \\
\text { No. }\end{array}$ & Paper Name & Test Modules & Eye-Tracking & $\begin{array}{l}\text { Pattern } \\
\text { Recognition }\end{array}$ & Cost Efficient & $\begin{array}{l}\text { Implementation } \\
\text { (Large Scale \& } \\
\text { Remote Areas) }\end{array}$ \\
\hline 1. & $\begin{array}{l}\text { ML to detect dyslexia } \\
\text { - Kohli and Prasad }\end{array}$ & & & & & \\
\hline 2. & $\begin{array}{l}\text { Risk of development } \\
\text { dyslexia } \\
\text { - Costa et al. }\end{array}$ & & & & & \\
\hline 3. & $\begin{array}{l}\text { Dyslexia tests } \\
\text { - Loizou \& Laouris }\end{array}$ & & & & & \\
\hline 4. & $\begin{array}{l}\text { Dyslexia using EEG } \\
\text { Wilckeetal }\end{array}$ & & & & & \\
\hline 5. & $\begin{array}{l}\text { Framework For Detecting } \\
\text { Dyslexia } \\
\text { (Proposed Project) }\end{array}$ & & & & & \\
\hline
\end{tabular}

\section{CONCLUSION AND SCOPE}

We have presented our ongoing research outcome on identifying dyslexia pattern automatically to help each school or parents identifying dyslexic students. We have used Eye-Tracking, multimedia capturing, storage, analysis and retrieval with the support of big data analytics. The multimedia is captured during examination time and presented to the doctor for getting a semantic view of the exam time user hand and eye movement, which is a prime source of finding dyslexic patterns. We are in the process of applying the framework on a national level to check the performance of the serve side auto-grading algorithms. Our findings will help us in developing assistive technologies for the dyslexic children with moderate S learning environment in the school. Future Scope

Involves Development of a System or Game which will help cure these Dyslexic Children.

\section{ACKNOWLEDGEMENT}

It gives us a great pleasure in presenting the paper on "Framework for Detecting Dyslexia". We would like to take this opportunity to thank Dr. Pankaj Agarkar, Head of Computer Engineering Department, DYPSOE, Pune for giving us all the help and support we need during course of the Paper writing work. We are really grateful to him. Our special thanks to Dr M. Z. 
Shaikh, Principal DYPSOE who motivated us and created a healthy environment for us to learn in the best possible way. We also thank all the staff members of our college for their support and guidance.

\section{REFERENCES}

[1]. Towards a Game to Detect Dyslexia. In Proc. of the 17th Int. ACM SIGACCESS Conference on Computers \& Accessibility. ACM, New York, NY, USA, 307-308.

[2]. A Serious Game for Predicting the Risk of Developmental Dyslexia in Pre-Readers Children," in Computer Communications and Networks (ICCCN), 2012 21st International Conference on, vol., no., pp.1-5, July 30 -Aug. 2 2012.

[3]. The implementation of interactive multimedia in early screening of dyslexia," in Innovation Management and Technology Research (ICIMTR), 2012.

[4]. Dyslexia diagnosis in reading stage though the use of games at school," in Computer Games (CGAMES), 2012 17th International Conference on, vol., no., pp.12-17, July 30.

[5]. Dyslexia diagnosis in reading stage though the use of games at school," in Computer Games (CGAMES), 2012 17th International Conference on, vol., no., pp.12-17, July 30.

[6]. Web readability for students with Dyslexia: Malaysian case study," in User Science and, engineering 2014 3rd International Conference on, vol., no., pp.192-197, 2-5 Sept. 2014.

\section{Cite this article as :}

Suyash Thonte, Risha Saxena, Shubham Swami, Onkar Kamthe, Prof. Pallavi Shimpi, "Framework for Detecting Dyslexia", International Journal of Scientific Research in Science and Technology (IJSRST), Online ISSN : 2395-602X, Print ISSN : 2395-6011, Volume 6 Issue 6, pp. 245-248, November-December 2019. Available at doi :

https://doi.org/10.32628/IJSRST19669

Journal URL : http://ijsrst.com/IJSRST19669 